\title{
Surprising ECG pattern suggestive of an anterior wall ischaemia in a patient with occluded distal LCX and non-occlusive RCA disease
}

\author{
Navin Agrawal, Apurva Vasavada
}

Department of Cardiology, Tristar Hospital, Surat, Gujarat, India

\section{Correspondence to}

Dr Navin Agrawal,

drnavinagrawal@gmail.com

Accepted 12 November 2014

CrossMark

To cite: Agrawal $\mathrm{N}$ Vasavada A. BMJ Case Rep Published online: [please include Day Month Year] doi:10.1136/bcr-2014208136

\section{DESCRIPTION}

Conventionally, ECG has been the gold standard in culprit artery localisation and triage for management of acute coronary syndrome. The anterior wall ischaemia/infarction involving the left anterior descending artery (LAD) is usually represented on the ECG with ST-T changes in the precordial leads and in leads I and aVL while those of the inferior wall classically involve leads II, III and aVF. ${ }^{1}{ }^{2}$ Occurrence of an anterior wall infarction on the ECG without involvement of the LAD is extremely uncommon and seldom described in the literature. We present an interesting case of a middle-aged man who presented with a 2-day history of acuteonset chest pain and who was diagnosed with an evolved anterior wall myocardial infarction, on the basis of an ECG performed elsewhere (figures 1 and 2). The patient was managed conservatively after admission, and was advised a coronary angiogram and revascularisation accordingly. The echocardiogram revealed hypokinesia of the inferior and posterior wall, which was not consistent with the ECG pattern of the patient. The angiogram surprisingly revealed non-occlusive disease of the mid right coronary artery (RCA) with diffuse disease of the distal RCA branches and occlusion of the distal left circumflex (LCX) vessel while LAD was completely normal (figures 3-5 and videos 1-3). The patient was given the option of revascularisation of LCX versus medical management in view of the small calibre of the culprit vessel, of which the patient opted for medical management. The patient was subsequently discharged on medication and has been stable on follow-up.

The surprising aspect of the presentation of this patient was the fact that the ECG on presentation had coving of ST segments in the leads I, aVL and most of the precordial leads with deep asymmetrical $\mathrm{T}$ wave inversion in leads $\mathrm{V} 3-\mathrm{V} 6$, while in contrast to the conventional belief there were no changes in the leads II, III and aVF, which are classically considered to be associated with inferior wall infarction as was documented on angiogram by the complete occlusion of the LCX. The presence of an ECG suggestive of an evolved/non-ST elevation anterior wall infarction pattern in a case of distal LCX infarct is a novel and inexplicable finding.

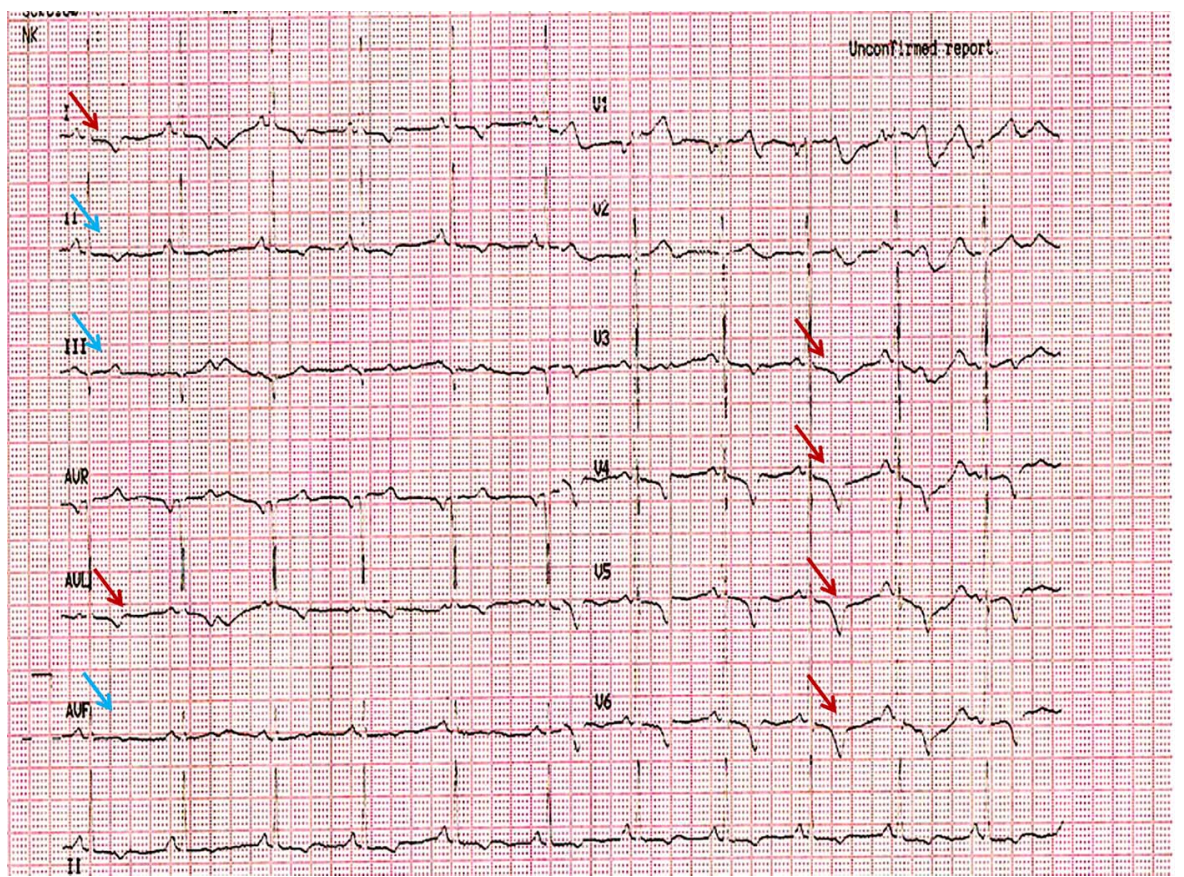

Figure 1 Referring ECG of the patient showing significant ST-T changes in the precordial leads with no ST elevation in the inferior leads. The red arrows point towards coved ST segments and T wave inversions in leads I and aVL and precordial leads while the blue arrows point towards absence of infraction-related changes in leads II, III and aVF. 
Images in...

Figure 2 ECG taken in our hospital showed further development of changes in anterior precordial leads with no changes in inferior leads. The red arrows point towards coved ST segments and T wave inversions in leads I and $\mathrm{aVL}$ and precordial leads while the blue arrows point towards absence of infarction-related changes in leads II, III and aVF.

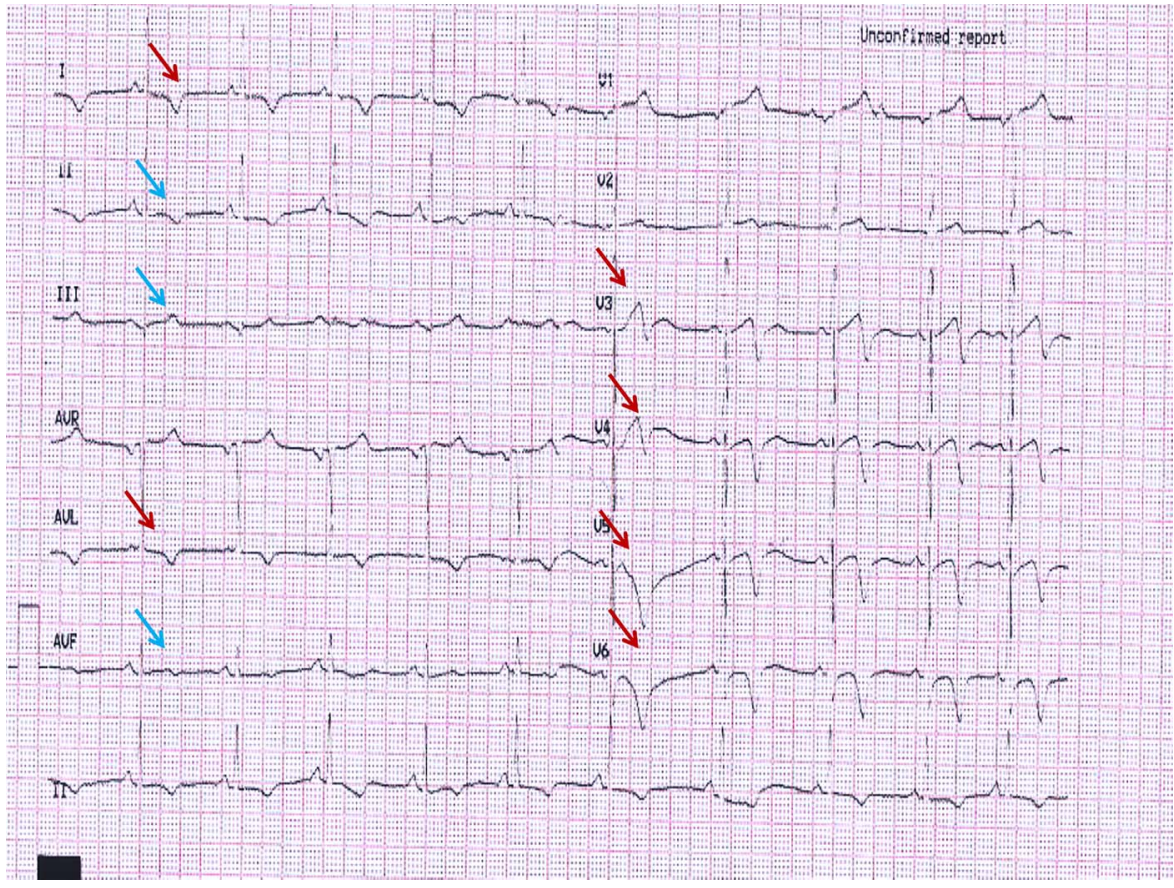

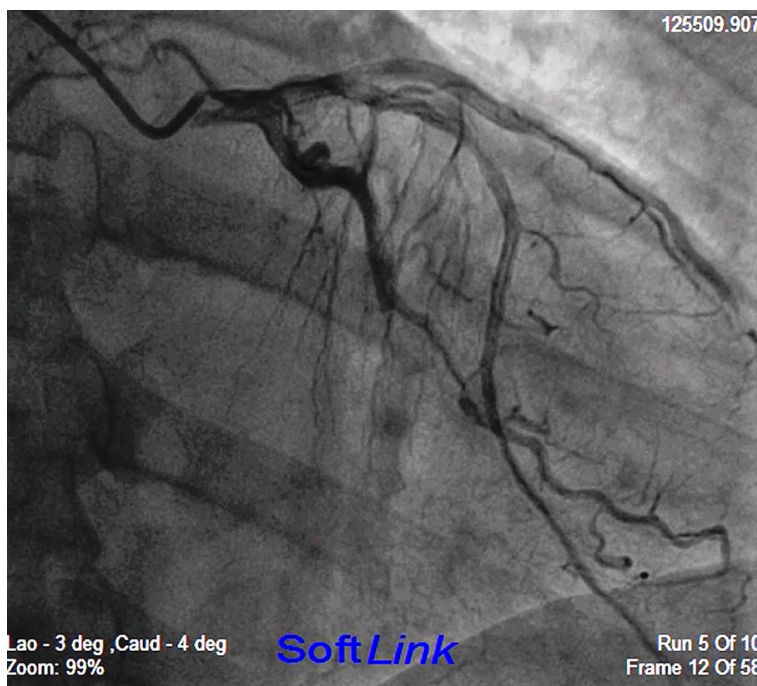

Figure 3 Angiogram in posteroanterior caudal view showing occlusion of the distal left circumflex with normal flow in the left anterior descending artery.

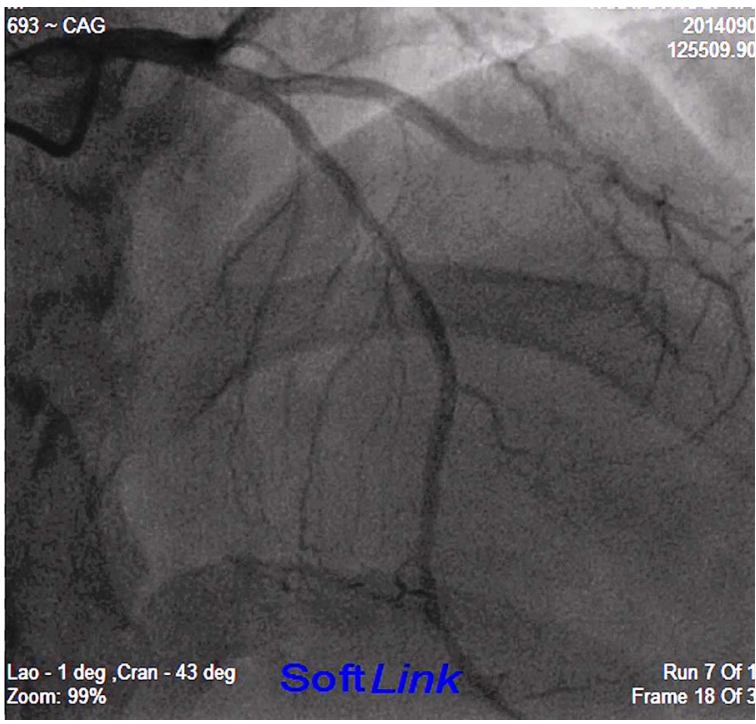

Figure 4 Angiogram in posteroanterior cranial view showing normal flow in the left anterior descending artery with no flow-limiting lesion. 


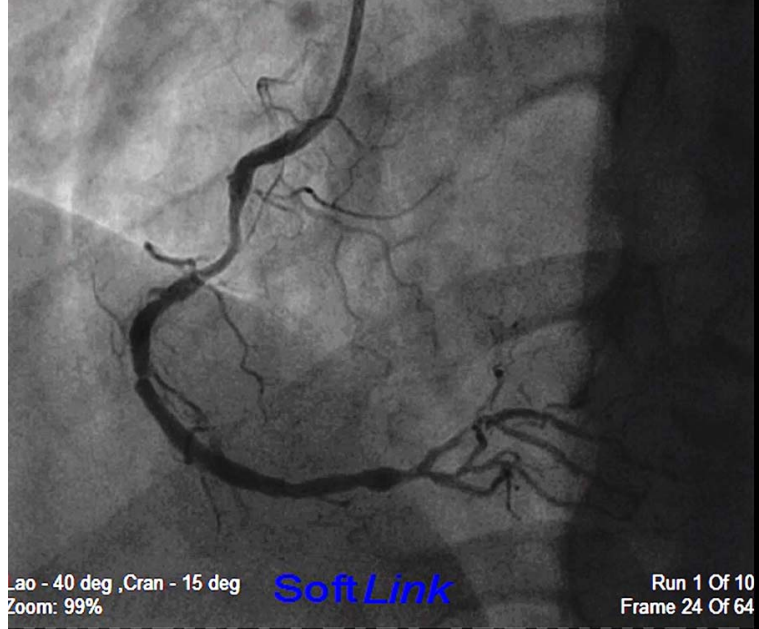

Figure 5 Angiogram in left anterior oblique cranial view showing normal flow in the right coronary artery with a critical stenosis proximally.

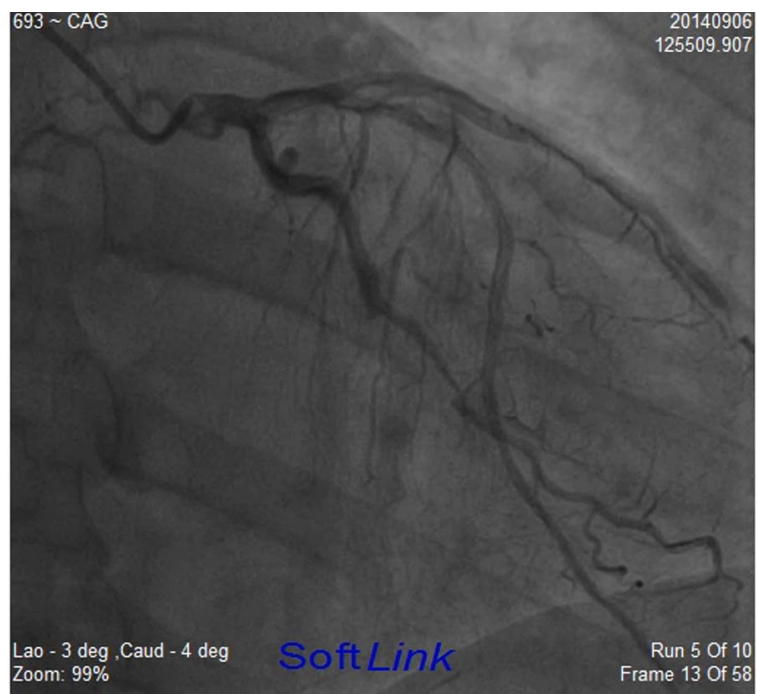

Video 1 Angiogram in posteroanterior caudal view showing occlusion of the distal left circumflex with normal flow in the left anterior descending artery.

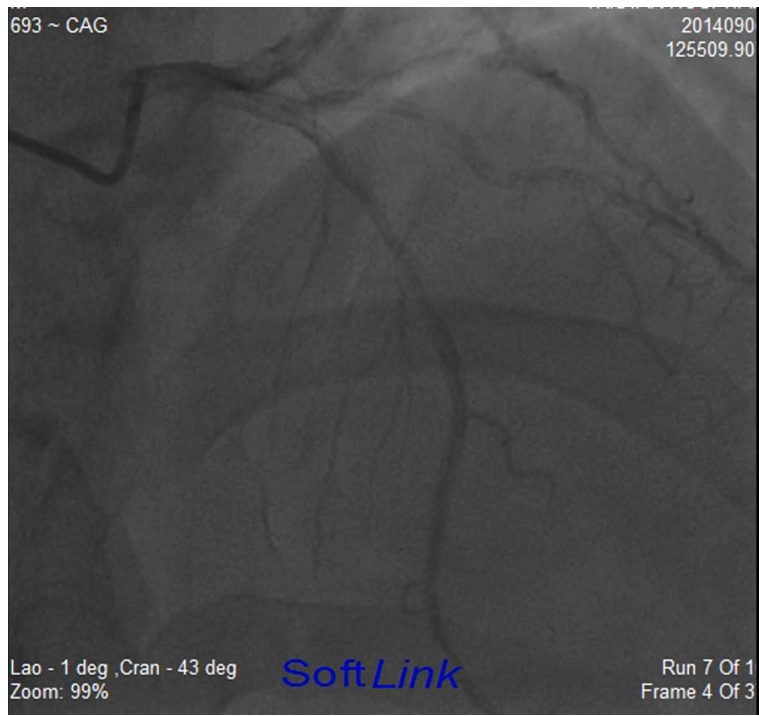

Video 2 Angiogram in posteroanterior cranial view showing normal flow in the left anterior descending artery with no flow-limiting lesion.

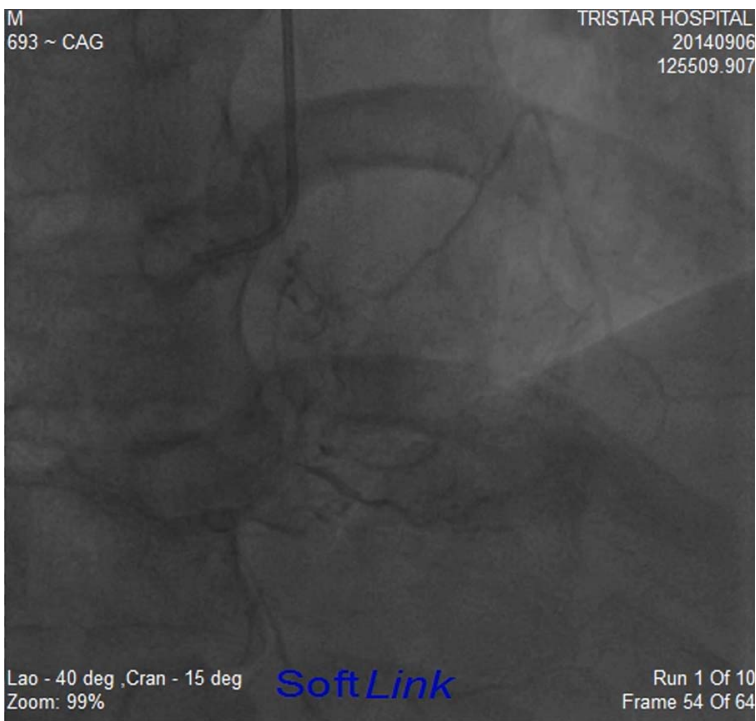

Video 3 Angiogram in left anterior oblique cranial view showing normal flow in the right coronary artery with a critical stenosis proximally.

\section{Learning points}

- The presence of an evolved anterior wall infarction pattern on the ECG with no changes in the inferior leads with a completely normal left anterior descending artery on the angiogram is an inexplicable and previously unreported finding.

- This case challenges the efficacy of ECG in localising the culprit vessel of infarction and in deciding the plan of intervention.

- Echocardiography is usually superior in culprit artery localisation in comparison to an ECG but the interpretation is usually operator dependent and requires significantly higher skill and expertise in comparison to an ECG.

- A multipronged strategy should be adopted to guide the approach of management in the setting of an acute coronary syndrome.

- Complete occlusion of artery can present with ST segment depression, which should not be missed during interpretation of ECG in patients presenting with acute coronary syndrome.

\section{Competing interests None.}

Patient consent Obtained.

Provenance and peer review Not commissioned; externally peer reviewed.

\section{REFERENCES}

1 Alpert JS, Thygesen K, Antman E, et al. Myocardial infarction redefined-a consensus document of The Joint European Society of Cardiology/American College of Cardiology committee for the redefinition of myocardial infarction. J Am Coll Cardiol 2000;36:959-69.

2 de Zwaan C, Bär FW, Wellens HJ. Characteristic electrocardiographic pattern indicating a critical stenosis high in left anterior descending coronary artery in patients admitted because of impending myocardial infarction. Am Heart J 1982;103 (4 Pt 2):730-6. 
Copyright 2014 BMJ Publishing Group. All rights reserved. For permission to reuse any of this content visit http://group.bmj.com/group/rights-licensing/permissions.

BMJ Case Report Fellows may re-use this article for personal use and teaching without any further permission.

Become a Fellow of BMJ Case Reports today and you can:

- Submit as many cases as you like

- Enjoy fast sympathetic peer review and rapid publication of accepted articles

- Access all the published articles

- Re-use any of the published material for personal use and teaching without further permission

For information on Institutional Fellowships contact consortiasales@bmjgroup.com

Visit casereports.bmj.com for more articles like this and to become a Fellow 